\title{
GROGGY AND WITH TIED HANDS: THE FIRST CONTACT WITH THE NEWBORN ACCORDING TO WOMEN THAT HAD AN UNWANTED C-SECTION
}

\author{
Heloisa de Oliveira Salgado ${ }^{1}$, Denise Yoshie Niyㄹ, Carmen Simone Grilo Diniz ${ }^{1}$
}

\begin{abstract}
Objective: to describe and analyze the experience and feelings of mothers who had an unwanted Csection, with regard to the first contact with their newborn. Methods: this is a qualitative webbased research, whose call for participants was published in October 2011 on a social network of mothers website. The women were interviewed in regard to their experience with C-section, referred to as an unwanted outcome, invited to make narratives about the feelings associated with the experience of labor and childbirth and to the postpartum period. The analysis was conducted within a gender perspective. Results: the 20 women interviewed age ranged from 17 to 41 years, 19 women had studied for 12 or more years and were married or lived with a partner. Only two women remained with their newborns right after birth. The other ones were kept apart from their babies for periods that ranged between one hour (three women) and more than four hours (six women). Most women could not have a partner/companion during the immediate postpartum period, although in Brazil this is a right guaranteed by law. The majority had also suffered some kind of violence and many also regretted being under the influence of medication for sedation during their first contact with the newborn. Regarding this first contact, three groups were identified: women with feelings of fulfillment, those with ambiguous feelings, and those without any positive feelings about the first contact with their newborn. Conclusion: women referring to their C-section as an unwanted outcome had their frustration towards the birth experience amplified by the conditions of the first contact with their newborn. These conditions were negatively influenced by the immediate postpartum assistance routines.
\end{abstract}

Key words: cesarean section; mother-child relations; gender and health; violence against women; social networking.

\section{INTRODUCTION}

The number of women that report a high level of dissatisfaction with the childbirth experience has increased over recent years throughout the world ${ }^{1}$. Most of these women wold have preferred to have a natural birth but ended up having either a Csection or a childbirth carried out with interventions, so the experience of labor was more painful and, as a consequence, more likely to be assessed as unsatisfactory ${ }^{2,3}$.

In the last decade the same has occurred in Brazil. Many of these unsatisfied women have created and supported a health consumers' movement that has been gaining strength thanks to the Internet. It is in blogs, communities, electronic discussion lists and social web networks, among other web environments, that health consumers find official documents and evidence based information which report the best practices on pregnancy and childbirth care. ${ }^{4,5}$ The access to scientific information amplifies the women's dissatisfaction, since it allows them to realize that health institutions and professionals do not undertake the necessary changes to the assistance models, for they continue to believe in the safety and effectiveness of these non-recommendable or potentially harmful procedures. ${ }^{4,5}$ One of the recurring subjects among women is the dissatisfaction toward the C-section, mainly when the unwanted C-section is combined, from the women's point of view, with the occurrence of obstetrical violence ${ }^{6}$ during pregnancy and childbirth care.

The concept of unwanted C-section results from a process that involves the historical and social

\footnotetext{
1 Departamento de Saúde Materno-Infantil da Faculdade de Saúde Pública da Universidade de São Paulo. Corresponding author: hellosalgado@gmail.com
}

Suggested citation: Salgado HO, Niy DY, Diniz CSG. Groggy and with tied hands: the first contact with the newborn according to women that had an unwanted C-section; Journal of Human Growth and Development 2013; 23(2): 190-197

Manuscript submitted Sep 18 2012, accepted for publication Mar 292013. 
circumstances lived by the woman, her relationship network (virtual or in presence) and, mainly, the relationship of the woman with the health providers, the experiences of care received, the feeling of being respected during the whole assistance process, the first contact with their newborn and the postpartum experience ${ }^{6}$. This means that the report of an unwanted C-section is not only related to the frustration of not experiencing a normal birth but also to the whole experience of care, which involves the first contact with the newborn and the relationship with the health providers.

This research takes as reference the recent literature which has shown that 70 to $80 \%$ of women in private and public health sectors in Brazil prefer vaginal birth 7,8 in the early pregnancy, although total of $52 \%$ of women had C-sections in $2011^{9}$ and in the private health sector the proportion was $82 \%$ in $2010^{10}$.

Studies on safety in birth care indicate that healthy women who underwent a C-section, compared to those who had vaginal birth, showed more postpartum complications, ${ }^{11,12}$ less contact with the newborn ${ }^{11}$ and more problems in breastfeeding ${ }^{11-15}$. According to this, most Brazilian women do not deliver their children as they first wanted, and further, they face additional physical difficulties caused by the C-section, factors which can fogether contribute to an even worse assessment of the childbirth experience.

Added to this begivaing, there is an extremely tolerant culture of disrespect and abuse in the assistance given to mothers, a topic which is arousing ever greater interest in the Brazilian case.

The term obstetrical violence is being consolidated by the women's movement as a variation of "violence in childbirth care", already described in the literature, and which comprehends any kind of violence that may occur during pregnancy, birth and postpartum, including the abortion situation. Brazilian researchers reviewed the international literature concerning violence against women in health-care institutions ${ }^{16}$ and they were able to identify and describe four categories: negligence, physical violence, verbal violence and sexual violence. However, in the case of obstetrical violence, it is necessary to include a fifth category, which may or may not derive from the others, since it creates an intense emotional register in the women who suffer from it: psychological violence ${ }^{6}$.

Through many decades different authors have researched the building up of the attachment between mother and newborn, from pregnancy to toddlerhood, as a way of understanding how these paramount relationships are set and how they are connected to social, emotional, physical and cognitive development in newborn ${ }^{1}$ and child and also to the relationship model which will be established by them throughout their lives ${ }^{17,18}$. "A mother's emotional attitude guides the newborn, providing quality of life to her experience and serving as an organizer of her psychic life by enabling identifications that may influence her subsequent development" (Borsa, 2007) ${ }^{18}$.

Childbirth is one of the most fundamental moments in the process of the construction of the mother-newborn attachment since it materializes motherhood, which was built over the months before childbirth. Also, it is effectively the first contact of the mother with her newborn, the moment to reorganize emotional expectations and fantasies about the child that was being generated and when the woman recognizes herself as a mother.

Moreover, the early contact between mother and newborn also determines relevant outcomes concerning physiological processes which take place thereafter: the afterbirth, the reduction of his, bleeding the stimulation of milk production and the onset of breastfeeding ${ }^{19}$.

Currently, new perspectives on the quality of childbirth care take into account that the experience of "good delivery" for women and newborns involves indicators of well-being and physical and emotional integrity, informed choices made by women as well as the respect for women's and newborns' rights ${ }^{20}$ which includes being free from abuse or violence during care.

There is little knowledge about Brazilian women's experience in their first contact with their newborn, since the stay of the newborn in the nursery and its separation from the mother for long periods were part of the routine care for many decades. Only recently, with new perspectives on the importance of early contact in promoting physical and mental health for mothers and newborn, has the topic aroused great interest. This study describes and analyzes the first contact mother-newborn of middle-class women who live in urban areas and who report unwanted C-section, their feelings associated with this first contact, and how they assess the influence of this contact on their motherhood experience.

\section{METHODS}

The current research is part of the master's degree dissertation "The experience of unwanted C-section: women's perspectives on decisions and their implications at labor and birth"6 which was carried out under the main protocol "Risks and benefits of childbirth care: perspectives of users and professionals".

This research was based on a qualitative approach and was guided by the perspective of social gender relations. By gender, we understand sex as socially constructed, e.g., the way that notions of feminine (female) and masculine (male) are constructed and deconstructed in social relations as a whole ${ }^{21}$ and in the case at hand, in the interactions of maternal health care. The gender assumptions that modulate maternal health care include the belief in the unreliable female body, that 
supposedly demands guardianship and correction from providers and institutions. These beliefs lead to the overestimation of the benefits of interference in childbirth, and the underestimation, or even invisibility of the adverse effects of interventions ${ }^{22}$. One of these underestimated, or even invisible aspects, is the experience of an unwanted cesarean section, and its impact on the welfare of women and children.

When a woman and her newborn survive childbirth without any significant harm to their health, it is expected from her that she be satisfied and grateful no matter how painful this experience might have been. The emotional experience of childbirth seems to be irrelevant when considering the "outcome" of childbirth: mother and newborn alive. The level of acceptance of C-section as a necessarily positive experience, even for women who actively sought to avoid it, usually imposes silence, the inadequate feeling of "shame" and some lonely suffering to the women that got frustrated with the birth experience of their children.

However, in recent years, internet connectivity has made it possible for women to share stories and to create communities that, when sharing their experiences and their sense of injustice, organize themselves for joint action creating dissident narratives. ${ }^{4,5}$ These dissident narratives claim a "desire to give birth", unthinkable in the culture of care, and this establiches itself as a "conceptual instability" of gender, since birth in Brazilian culture is interpreted as an indignity to be prevented. The proposals arising from these movements, from a better oriented care to a physiological and woman-centered birth and more based on scientific evidence, face serious conflicts of interest and resistance to change ${ }^{23}$.

In addition to gender references, we used the notion of childbirth and maternity proposed by Gutman" ${ }^{24}$ who understands that "There are few women who can see themselves reflected in the childbirth they have just been through. The deliveries are not good or bad, but the experience of every mother is essential to understand their later difficulties in early bonding with their child." The author also makes an up-to-date criticism the routines and services, which are not really aware of the "emotional price" that these women have been "paying" for the childbirth experience they have been going through. This research aims at this "emotional price".

Through a flexible script of questions, women were interviewed about their unwanted C-section experience and their postpartum period. Such research was approved by the Research Ethics Committee (Protocol n. 0110.0.207.000-11).

Initially, it was found that an increasing number of women share their feelings about motherhood on social media. Through these media, women express their fears about childbirth, their dissatisfactions with childbirth and their difficulties with their own care; the care of their newborn; breastfeeding; getting back to work and sex life, among other issues related to motherhood.

The invitation to take part in the research was published in October 2011 via Facebook, on the researcher's page, and shared in many murals and friends of friends' pages ${ }^{6}$. It was requested that women who had had a cesarean considered unwanted ("reported unwanted C-section") should get in touch with the researcher via e-mail. A total of 36 women were available to participate in the study, and all of them received the questionnaire prepared by the researcher via e-mail. Twenty-two (22) women sent the completed questionnaire and two interviews were not used for analysis because the respondents did not replied the researcher contact.

To collect data, a Word form was composed with a list of questions and was used to search for prior information: family history of labor and delivery; pregnancy; wishes and choices during pregnancy; antenatal care; childbirth, postpartum and breastfeeding; negotiation with health professionals; support networks and feelings at the various stages of pregnancy, childbirth and postpartum.

This form was tested at two different moments, featuring two pilot forms. A first pilot form, inspired by the concept of self-ethnography as a methodology ${ }^{25}$ was drawa up with the lead researcher, who understands the situation as she nearself experienced an unwanted cesarean, and whose answers pointed out the reed for important adjustments to the script; and another composed of eight interviewees. The women interviewed in the second pilot group were invited to comment on the instrument in order to collaborate in the preparation of its final format, that was thenrevised based on the responses and comments. After completion of that version, the script was sent to all the women, and additional questions were seen as necessary to supplement the data and to enable all the completed scripts to be analyzed.

This research was not aimed to ensure sample representativeness, since the sample was intentionally self-selected not only for the women's high social capital (reflected in the extensive use of social media), as for what we are now calling "desire to narrate": the desire to tell and make sense out of their experience, which can be considered a standard precisely to this apparently growing segment of women.

Thematic analysis ${ }^{26}$ of the empirical material was performed based on the discussion of gender and maternal health proposed by Diniz ${ }^{22}$. The typical models of birth care assistance, in both public and private sectors, calll for an understanding of how gender assumptions guide the interpretation of the female anatomy and childbirth physiology, and how the interventions made in the woman's body, as well as the routines and expectations of the health assistance personal, are the expression of such social relations. 
For the evaluation of practices we referred to "Guide to effective care in pregnancy and childbirth"19 in order to contrast the international scientific consensus on safe and humanized childbirth care with the actual practices in Brazil, characterized by the over medicalization of childbirth and the excessive and unnecessary use of interventions ${ }^{10}$. This overuse of interventions will be interpreted here as the expositor of social gender relations in care, e.g.: the way medical interventions reinforce power relations, often invisible because they are taken as merely technical, not as rights violations of nights.

\section{RESULTS}

Regarding the women interviewed (20), the age group was varied (between 17 and 41 years), half of them (10) lived in the State of São Paulo and the others in different regions of the country (Central, South, Southeast and Northeast). Fifteen (15) were living in their State Capital at the time of the birth. Except for one woman, nineteen (19) had 12 or more years of study and were married or lived with a partner. The range of time since they had undergoal the C-section was four months to seven years.

Based on thematic analysis, some aspects considered relevant by the women in their experience of the first contact with the newborn were selected to be analyzed: "to receive the newborn with tied hands", "to be unaccompanied and without the newborn in the immediate postpartum", "to feel abandoned with the newborn during rooming-in" and "the erasure of memories" caused by uninformed and unconsented use of drugs with amnesic effects.

\section{The first contact with the newborn}

Despite all the recommendations on the importance of the mother-newborn contact in the first hour, among the women interviewed, two remained with the newborn soon after birth and three were separated from their child for less than an hour. The others were separated for an hour or more and six were removed for over four hours.

The neglect of emotional and relational aspects of care in the immediate postpartum period was a constant. Most reported the fact that they remained alone after the $\mathrm{C}$-section, during recovery from anesthesia and "forgotten in the corner", without having someone to speak to or to inform about the newborn, than situation already described by Lino $(2010)^{27}$ as being a typical C-section experience. As reported by DAIANE:

"After the suture, I was taken to what must have been the recovery room for about 40 minutes to 1 hour but it seemed much longer. The state of mental confusion remained, I had no contact with any of the team and I started feeling abandoned (...) immediately after surgery: I was carried out on a stretcher to what seemed like the corner of a hallway in the operating room and stayed there alone (...) without anyone to tell meabaut what was going on, and with confused thoughts because, I believe, of the thrill of the surgery or anesthesia. At that moment, I remember feeling very angry and treated as a part of the 'assembly line'."

In the reports, it because clear that even when the woman was able to stay with her newborn after the surgery, by procedures were carried out in a disrespectful and unsafe way despite the seek to protocols that aim humanized the athadence:

"Up to now it as been part of the routine of the maternity hospital to place the baby between the knees of the mother, as we do not feel our legs, so the baby does not fall from the stretcher. Nobody helped me, I could not lift my head to see if any thing was bothering, I could not get to her, and there was nobody else in the recovery room. There were two assistants circulating between 6 or 8 beds. I worked at that maternity hospital later on and was able to see that was that routine. (...) I was there for about an hour or an hour and a half with the baby between my legs. [And if the baby cries, and the assistants are busy, does she keep on crying? Is there a way of calling the assistants?] She keeps on crying because there is no bell, no companion to help or to call someone, so the mother MUST wait for someone to decide and come" (CAROLINA).

\section{Feelings experienced by the women}

Three categories of feelings experienced by the women, during the first contact with the newborn, were identified in the reports of the interviewees: feelings of 'fulfillment' (three of them), 'mixed feelings' (ten) and 'not having positive emotions towards their child (seven).

Among women who reported feelings of fulfillment, all reported having breastfed their baby in the first hour after the cesarean section, as reported by ANITA:

"Divine, being a mother to me has always been the most important part of my life. Seeing that little beautiful girl, perfect, feeding on me, close to me and to her father, who was with us, was indescribable" (ANITA). Being in contact with the child soon after birth and staying with her as well as feeding her in the first hour after birth seemed to be associated with a better assessment of the experience of first contact for these women, as in the latest international recommendations (WHO, 2001).

Among women who reported ambiguity, some could touch or even take their newborn onto their laps for a few minutes; others could only see the baby with no possibility of touching it let alone meeting or recognizing the child that had just been 
born. Some of these women mentioned that they only saw their child when they were already in three room, after recovery and still overwhelmed with emotion or under the effect of sedation:

"As soon as they carried out the 'standard procedures', the nurse brought him to me, showed me he was perfect and put him in my arm. I was still a little confused but excited. It seemed hard to believe that I had a son. Soon she took him back and I expected the doctor close my belly in the reflection of the light, I saw him as he seemed to be cleaning my belly, and then I think I slept" (JULIANA).

Among women who reported not having positive feelings, there is a clear reference to frustration with the childbirth, the first contact with the newborn and the postpartum:

"Honestly, it was not as I had expected. It seemed that there was no connection between me and the baby and I believe that much of this feeling was due to the C-section. I am saying this because I could not hold him or feed him as I had imagined. I had the illusion that because the labor should have been 'humanized', I would pick him up in my arms right after the delivery and place him close to my chest, hold and caress him while breastfeeding. However, as I bad a C-section, my arms are immobilized and I could not touch him. When feeding him, my husband, with the help of the pediatrician, had to stand holding him to my breast, which was an uncomfortable position for everyone. Even though I got a chance to nurse him at that moment, and feeling thrilled, I still did not feel like a mother. I only managed to create that bond through physical contact almost a month after the birth, because the pain of the C-section would not let me hold my baby the way I would have liked to" (HELOISA).

Six women spontaneously commented that they had their arms tied, and only one of them mentioned that they were untied at her request, so she could welcome her baby, even though she was concerned not to disrespect the institutional protocols:

"After the baby was born, he was placed beside me, my hands were untied, and I could caress him for a while. I looked at the pediatrician and asked if I should be doing that (I was wondering if I was disrespecting some protocol by not returning the baby quickly), and he said he was giving me what I had asked for. A little later, he asked my permission to examine the baby, which was done in a transparent crib beside me" (REGINA).

This initial contact right after birth was referred as very important for those women who could experience it. For those who could not touch their child or could only see it, the first contact a few hours later seemed "clunky" with reports of not feeling like being the mother of that child and not recognizing her as their child, as in the testimony of NATÁLIA:

"My hands were tied so when she was born I only saw her briefly in the postoperative room, when she was placed in my laps or they my arms and I could pick her up for the first time. I had a hard time believing that she was mine. It was weird to smell her, to feel her skin, it was a strange sensation, and it was clumsy. (...) I didn't feel like a mother and did not recognize her as my daughter, I felt like a C-sectioned cow. The feeling of defeat and assalt excluded good feelings, although I was grateful that she had been born healthy and well. (...) I was really depressed about everything that happened at the birth of my daughter, I think it influenced a lot, I did not feel that explosion of love, I was not a mother, it seemed that I had slept pregnant and happy and awakened sad and with a strange baby in my arms (admitting this is very painful to me, but I feel ashamed and I like a criminal) " (NATÁLIA).

Natália's report not only highlights the weirdness she felt when she held her baby for the first time, caused by the contract between what she had planned and what was experiencing, it also brings out the obstetric violence experienced. She said that the violence was largely responsible for the emotional distress experienced:

"At the hospital I was disrespected (...) They had performed more than 10 vaginal exams in the space of 4 hours, laughed at me, doubted my pain, made fun of my choice of birthing center, tried to prohibit the company of my husband, restricted my movements, swore at me for having wet hair, doubted my contractions, did not believe my words" (NATÁLIAV).

For the other women who reported negative or mixed feelings at the first contact with their newborn, there seems to be a mixture of frustration experienced by an unwanted C-section and by the restricted contact with the child had was just been born. Women who reported great frustration with the experience of an unwanted caesarian evaluated the first contact more negatively.

Eight women reported having been sedated after surgery and being still "groggy" when they received their child for the first time and only one was informed that she would be sedated, even though she asked not to be.

"I asked not to be sedated (...), but they didn't listen to me" (FLAVIA).

Although a few women were warned that they would receive a medication that would sedate them, they report not being informed about the risks (physical and emotional), to themselves and their babies, of this type of medication, according to reports CLARISSA'S and JULIANA'S reports: 
[How was the C-section?] "Horrible, I was tied up, my daughter was soon taken away from me, and I only saw two hours later. After the delivery I think I was sedated, because I can only remember a little, including how I got to the room. (...) [How was your first contact with your baby?] I felt joy, I wanted to nurse soon, her immediatly but I was still groggy" (CLARISSA).

"I remember having gone to the room still 'groggy', there is a video that my husband made to record the first feed, my sister was in the room, the nurse was giving me instructions but I only remember it because of the video." (JULIANA)

\section{DISCUSSION}

Several studies around the world seek to understand how women are using internet resources and social media as a way to share experiences and information ${ }^{28}$, especially to stop the typical urban center isolation of the postpartum experience.

In a study on traumatic birth carried out by Beck $^{29}$ using e-mail interviews, women reported important benefits from participating in the survey: the feeling of being heard and recognized by someone experienced; realizing that you are not alone; writing your story of birth/trauma as a way of establishing the facts and details of what had happened; the feeling that now that everything is written and registered, it is possible to express the feeling; feeling empowered; feeling that someone "gave you a voice" (or listened to it) and the feeling that sharing your experience, you are helping other women to get over it. This research showed the same benefits mentioned by almost all of the participants who reported their satisfaction at participating in this research: the validation of their feelings by meeting with a community of women who share their dissatisfaction with the experience.

\section{Without their newborn and unaccompanied}

Most women were kept away from the newborn for a relatively long time immediately after birth, an important period for the establishment of the first contact between them, when mother and child are physiologically prepared for this meeting. In addition to both of them being in a period of alertness, studies show that the smell, the hearing and even the sight of the newborn are completely adapted to this first contact, which facilitate the bonding, as well as the breastfeeding $30,31$.

In this research, the reason for early separation between mother and newborn was the rigidity of hospital protocols. When a woman undergoes cesarean section, the contact with her child at birth is most often limited or just does not occur. In part, this can be explained by the fact that it is a major surgery, in which the woman is anesthetized, usually immobilized, often still under sedation, feeling passive and insecure ${ }^{6}$ and not rarely the newborn needs special care, especially when the procedure was elective, with no labor. Elective C-section is the main factor associated with the birth of preterm newborns and /or with some level of breathing discomfort ${ }^{32,33}$.

Generally, the emotional aspects are neglected, which reinforces the notions of hierarchy, thus the professionals' and institutions' needs prevail over those of the women. In addition, women's isolation and abandonment are typical of their post-cesarean ${ }^{27}$ experience, a fact that was also clear form the report of the interviewees.

This abandonment, besides being a situation of obstetric violence (psychological neglect/ abandonment), is also the violation of a Brazilian law (n. 11.108), also known as "The Law of the Companion"34 (Chapter VII - on the subsystem of companions during labor, delivery and immediate postpartum) (BRAZIL, 2005):

"Art19-J. The health services of the Brazilian Unified Health System,2 or private health insurance or the network itself, are obliged to permit the presence, beside the laboring mother, of one (1) companion during labor, delivery and immediate postpartum.

$\S 1^{\circ}$ The companion mentioned in the caput of this Article will be chosen by the woman."

Thus, reports of abandonment and isolation after cesarean sections are unjustifiable and unacceptable.

\section{The "rooming-out care" and erased memories caused by sedatives}

In the women's first contact with their newborn, the assistance includes a veiled form of violence, which is included in to hospital protocols. These protocols, as they are called by the health providers, only aggravate the situation of abandonment already reported, characterizing, for example, the "rooming-out" as a sad parody of the well-known and important "rooming-in care".

Tying women's arms during surgery is one of the protocols considered by many women as a kind of obstetric violence, used as a justification to avoid contaminating in the surgical area. However, it is not justified, mainly at the end of the cesarean, when women could have their arms untied to facilitate contact, with no injury to the safety of either.

That is why many women feel that they were deprived of the first contact with their child (touch, acknowledgement, welcome, feeding the baby), being subjected to an institutional protocol that does not contribute to the mother's or child's welfare by using protocols that are not evidence-based. In addition to the physical discomfort that the tied arms 
represent, there is therefore a symbolic dimension of not being able to receive and accept the child that has just been born.

The reference to sedation described by these women as a routine and its effects on the experience of childbirth were unexpected findings of the present study and should be further investigated. This is considered by women a harmful, disrespectful practice that should be analyzed within the perspective of obstetric violence (enforcement of an unnecessary and potentially harmful procedure, without informed consent), causing physical risk to the newborn who is being received and breastfed by mothers, according to their words, while still "groggy" (under the effect of sedation).

The gender approach enabled us to understand why technically inadequate and potentially harmful procedures (such as the abuse of the recommendation of cesarean section and the premature separation of mother and newborn) are accepted so passively. Although they are contrary to scientific evidence, such procedures reinforce the gender assumptions that justify the inadequacy of the female body, contempt for their genitals and bodily functions, which are considered primitive, slow and unpleasant and therefore should be corrected by a cesareansection. These gender assumptions are also reflected in the preference for the woman's passive position during childbirth (when they are "processed" by the system that "carries the labor out", considering the woman incapable of doing it herself) and giving priority to the interests of institutions and professionals as well as to their schedules instead of the women's and newborn's needs ${ }^{23,35}$.

Whereas the literature suggests appropriate care for women during labor/delivery as fundamental to the establishment of the mother-newborn bond, and that stressful childbirth experiences are associated with lesses success in breastfeeding and the delayed start of lactation process, it is necessary to look more carefully at how services are organized in order to provide safe and respectful care to women throughout the period of hospitalization. This includes ensuring the quality of early contact between mother and newborn and abolishing any

\section{REFERENCES}

1. Hodnett ED. Pain and women's satisfaction with the experience of childbirth: a systematic review. Am. J. Obstet. Gynecol. 2002;186:S160-72.

2. Domingues RMSM, Santos EM, Leal MC. Aspectos da satisfação das mulheres com a assistência ao parto: contribuição para o debate. Cad. Saúde Pública. 2004;20:52-62.

3. Silva, AVR, Siqueira, AA F. O valor do suporte à parturiente: um estudo da relação interpessoal no contexto de um Centro de Parto Normal. Rev. bras. crescimento desenvolv. hum. 2007; 17: $126-35$. procedure/protocol associated with obstetric violence, such as routine, non-consented sedation.

Thus, women who report their cesareans as unwanted had their frustration with the experience of childbirth amplified by the first contact with the newborn, hampered by the care routines in the immediate postpartum period. Others reported adverse experiences including separation from their child shortly after birth for a period longer than one hour, the occurrence of negligence, non-consented interventions and other forms of obstetric violence. Moreover, the occurrence of unsafe procedures which are performed for institutional convenience include tying the hands during surgery, the use of drugs to sedate women after childbirth and the abandonment of the women in the immediate postpartum period (during recovery from anesthesia). All these events are enhanced by the culture of partial compliance - or total failure comply - with the Law of the Companion.

The quality of the first contact with the newborn, as reported by women, strongly influences the feelings experienced during the postpartum period. Even some women who had cesareans reported as unwanted have referred to feelings of fulfillment at the first contact with the newborn, especially when it was possible to have their companion around, at having contact with their child shortly after birth and feed at, thus characterizing a more respectful first contact.

It is thus possible to provide a more emotionally peaceful postpartum period, and to ensure that the first mother-newborn contact occurs immediately and in the fullest possible way, even when a cesarean occurs. For women who had an unwanted cesarean, ensuring a positive experience at the first contact with the newborn can help prepare and overcome the limits between what is desired and what is possible, a delicate balance which is specially needed when it comes to motherhood.

\section{Acknowledgements}

To CNPq for the concession of financial support (n. 132850/2011-7 and n. 402593/2010-3), and Fapesp n. 2011/18534-6.
4. Diniz CSG. Humanização da assistência ao parto no Brasil: os muitos sentidos de um movimento. Ciênc. Saúde Coletiva. 2005;10:627-37.

5. Leão MRC; Riesco MLG; Schneck CA; Angelo M. Reflexões sobre o excesso de cesarianas no Brasil e a autonomia das mulheres. Ciência e Saúde Coletiva, v. 1, 2012. p182.

6. Salgado HO. A experiência da cesárea indesejada: perspectivas das mulheres sobre decisões e suas implicações no parto e nascimento. Dissertação de Mestrado, Faculdade de Saúde Pública, Universidade de São Paulo, 2012, 155p.

7. Potter JE, Berquo E, Perpetuo IH, Leal OF, Hopkins K, Souza MR, et al. Unwanted caesarean sections among public and private 
patients in Brazil: prospective study. BMJ. 2001;323:1155-8.

8. Dias MAB, Domingues RMSM, Pereira APE, Fonseca SC, Gama SGN, Theme Filha MM, Bittencourt DAS, Rocha PMM, Schilithz AOC, Leal MC. Trajetória das mulheres na definição pelo parto cesáreo: estudo de caso em duas unidades do sistema de saúde suplementar do estado do Rio de Janeiro. Ciênc. Saúde Coletiva. 2008;13:1521-34.

9. Brasil. Ministério da Saúde. Datasus. Informações de saúde. Brasília, DF, 2010. [acesso em 16 outubro 2011]. Disponível em: http://www2.datasus.gov.br/DATASUS/ index.php?area $=02$.

10. Victora CG, Barreto $M L$, do Carmo Leal M, Monteiro CA, Schmidt MI, Paim J, Bastos FI et al. Lancet Brazil Series WorkingGroup. Health conditions and health-policy innovations in Brazil: the way forward. Lancet. 2011 Jun11; 377(9782):2042-53.

11. Bodner K, Wierrani F, Grünberger W, BodnerAdler $B$. Influence of the mode of delivery on maternal and neonatal outcomes: a comparison between elective cesarean section and planned vaginal delivery in a low-risk obstetric population. Arch. Gynecol. Obstet. 2011;283:1193-8.

12. Chalmers $B$, Kaczorowski J, Darling $E$, Heaman M, Fell DB, O’Brien B, Lee L; Maternity Experiences Study Group of the Canadian Perinatal Surveillance System. Cesarean and vaginal birth in canadian women: a comparison of experiences. Birth. 2010;37:44-9.

13. Perez-Rios N, Ramos-Valencia G, Ortiz AP. Cesarean delivery as a barrier for breastfeeding initiation: the Puerto Rican experience. J Hum. Lac. 2008;24:293-302.

14. Vieira TO, Vieira GO, Giugliani ERJ, Mendes CMC, Martins CC, Silva LR. Determinants of breastfeeding initiation within the first hour of life in a Brazilian population: cross-sectional study. BMC Public Health. 2010;10:760.

15. Zanardo V, Svegliado G, Cavallin F, Giustardi A, Cosmi E, Litta P, Trevisanuto D. Elective cesarean delivery: does it have a negative effect on breastfeeding? Birth. 2010;37:275-279.

16. D'Oliveira AFP, Diniz, SG, Scraiber LB. Violence against women in health-care institutions: an emerging problem. Lancet 2002;359:1681-5.

17. Rapoport, A, Piccinini, CA. Apoio social e experiência da maternidade. Rev. bras. crescimento desenvolv. hum. 2006; 16: 85-96.

18. Borsa JC. Considerações acerca da relação MãeBebê da Gestação ao Puerpério. Rev. Contemporânea Psicanálise e Transdisciplinaridade. 2007;2:310-21.

19. Enkin M, Keirse MJNC, Neilson J, Crowther C, Duley L, Hodnett E, Hofmeyer, J. Guia para atenção efetiva na gravidez e parto. 3. ed. Rio de Janeiro: Guanabara Koogan, 2005.

20. Maternity Care Working Party. Making Normal Birth a Reality. Consensus Statement from the Maternity Care Working Party: Our Shared Views about the Need to Recognise, Facilitate and Audit Normal Birth. London: NCT/RCM/ RCOG; 2007.
21. Barbieri, Teresita de. "Sobre la categoria de geìnero - una introduccioìn teìoricometodologica" In: AZEREDO, Sandra \& STOLCKE, Verena. Direitos Reprodutivos. Sapo Paulo: Fundaçapo Carlos Chagas/DPE, 1991, p. 25-46.

22. Diniz CSG. Gênero, saúde materna e o paradoxo perinatal. Rev. bras. crescimento desenvolv. hum. 2009;19:313-26.

23. Diniz SG; D'Oliveira AFPL; Lansky S. Equity and women's health services for contraception, abortion and childbirth in Brazil. Reproductive Health Matters. 2012;20: 94-101.

24. Gutman L. A maternidade e o encontro com a própria sombra: o resgate do relacionamento entre mães e filhos. São Paulo (SP): Editora BestSeller; 2010. p.41.

25. Holman Jones, S. (2005). Autoethnography: Making the personal political. In N. K. Denzin \& Y. S. Lincoln. (Eds.) Handbook of Qualitative Research, (2nd ed., pp. 763-791). Thousand Oaks, CA: Sage Publications.

26. Minayo, C. Pesquisa Social - Teoria, Método e Criatividade. Vozes. Rio de Janeiro, 1995.

27. Lino HC. O bem-estar no parto sob o ponto de vista das pacientes e profissionais na assistência obstétrica. Dissertação de Mestrado. Faculdade de Saúde Publica, Universidade de São Paulo, 2010, 171p.

28. Madge C., O'Connor H. Parenting gone wired: empowerment of new mothers on the internet? [acesso em 5 agosto 2012]. Disponível em: https://Ira.le.ac.uk/bitstream/2381/1403/1/ CM \% 20 social \% 20 and \% 20 cultural \% 20revised\%20submission\%20Apri\%202005.pdf

29. Beck CT. Benefits of Participating in Internet Interviews: Women Helping Women. Qual. Health Res. 2005;15:411-22.

30. Odent M. A cientificação do amor. Florianópolis (SC): Saint Germain; 2002.

31. Toma TS, Rea MF. Benefícios da amamentação para a saúde da mulher e da criança: um ensaio sobre as evidências. Cad. Saúde Pública. 2008;24:S235-46.

32. Bettiol H, Rona RJ, Chinn S, Goldani M, Barbieri MA. Factors associated with preterm births in southeast Brazil: a comparison of two birth cohorts born 15 years apart. Paediatr Perinat Epidemiol. Londres, 14(1):30-8, 2000.

33. Silva VLS, Santos IS, Medronha NS, Matijasevich A. Mortalidade infantil na cidade de Pelotas, estado do Rio Grande do Sul, Brasil, no período 2005-2008: uso da investigação de óbitos na análise das causas evitáveis. Epidemiol. Serv. Saúde. 2012;21:265-274.

34. Lei Federal no. 11.108, de 7 de abril de 2005. Dispõe sobre o Subsistema e acompanhante durante o trabalho de parto, parto e pós-parto imediato. [legislação na internet]. Brasília; 2005. [acesso em 10 de dezembro de 2012]. Disponível em: http://www3.dataprev.gov.br/ sislex/paginas/42/2005/11108.htm

35. Atrash HK, Carpentier R. The evolving role of public health in the delivery of health care. J. Hum. Growth Dev.2012; 22(3): 396-399. 